\title{
Gemini Surfactant with Unsaturated Long Tails for Viscoelastic Surfactant (VES) Fracturing Fluid Used in Tight Reservoirs
}

\author{
Feifei Huang, Chunsheng Pu,* Leichao Lu, Ze Pei, Xiaoyu Gu, Shujun Lin, Feipeng Wu, and Jing Liu
}

Cite This: ACS Omega 2021, 6, 1593-1602

Read Online

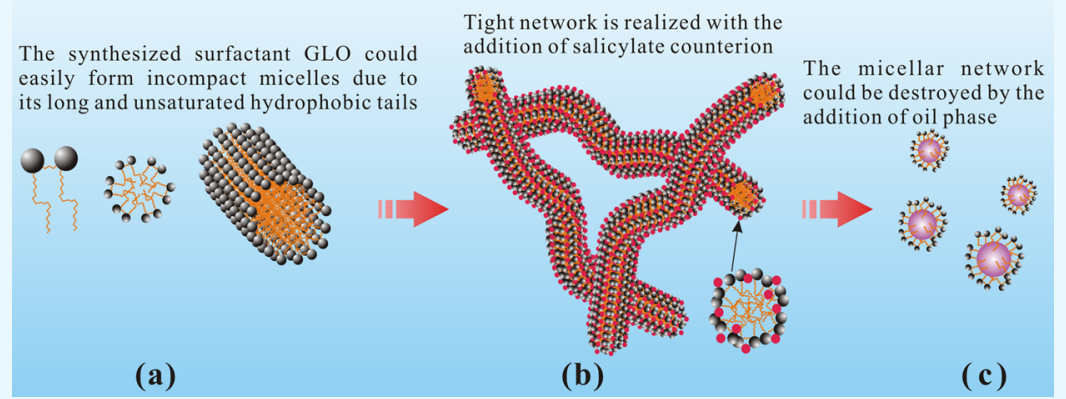

ABSTRACT: The high dosage of surfactant terribly restrains the extensive application of viscoelastic surfactant (VES) fracturing fluid. In this study, a novel gemini surfactant (GLO) with long hydrophobic tails and double bonds was prepared and a VES fracturing fluid with a low concentration of GLO was developed. Because of the long tails bending near the double bonds, there is a significant improvement of the surfactant aggregate architecture, which realized the favorable viscosity of the VES fluid at a more economical concentration than the conventional VES fracturing fluids. Fourier transform infrared spectrometry (FT-IR), nuclear magnetic resonance spectrometry $\left({ }^{1} \mathrm{H} N M R,{ }^{13} \mathrm{C} N M R\right)$, and high-resolution mass spectrometry (HRMS) were employed to study the formation of the product and the structure of GLO. The designed GLO was produced according to the results of the structure characterizations. The formula of the VES fracturing fluid was optimized to be $2.0 \mathrm{wt} \% \mathrm{GLO}+0.4 \mathrm{wt} \%$ sodium salicylate (NaSal) + $1.0 \mathrm{wt} \% \mathrm{KCl}$ based on the measurements of the viscosity. The viscosity of the VES fluid decreased from 405.5 to $98.7 \mathrm{mPa} \cdot \mathrm{s}$ as the temperature increased from 18 to $80{ }^{\circ} \mathrm{C}$ and reached equilibrium at about $70.2 \mathrm{mPa} \cdot \mathrm{s}$. The VES fluid showed a typical elastic pseudoplastic fluid with a yield stress of $0.5 \mathrm{~Pa}$ in the rheological tests. It realized a proppant setting velocity as low as $0.08 \mathrm{~g} / \mathrm{min}$ in the dynamic proppant transport test carried by GLO-based VES fracturing fluid. Compared to the formation water, the filtrate of the VES fracturing fluid decreased the water contact angle (CA) from 56.2 to $45.4^{\circ}$ and decreased the water/oil interfacial tension (IFT) from 19.5 to $1.6 \mathrm{mN} / \mathrm{m}$. Finally, the VES fracturing fluid induced a low permeability loss rate of $10.4 \%$ and a low conductivity loss rate of $5.4 \%$ for the oil phase in the experiments of formation damage evaluation.

\section{INTRODUCTION}

Tight oil reservoirs receive more and more attention for their enormous reserves and great exploitation potential. ${ }^{1-3}$ Largescale hydraulic fracturing is indispensable to improve the poor permeability and obtain economical production from these reservoirs. $^{4-8}$ Fracturing fluid is critical for the fracture generation and the proppant transportation during hydraulic fracturing. ${ }^{9,10}$ However, the conventional fracturing fluids damage the permeability of the reservoir matrix and restrain the conductivity of the fracture seriously because of the presence of the considerable insoluble residue and residual gel. $^{3,11-14}$ In recent years, viscoelastic surfactant (VES) fracturing fluid based on entangled micelles attracted huge attention due to its low-damage property (i.e., no insoluble residue and little residual gel). ${ }^{15-18}$ Nevertheless, the poor thermal stability of VES fluid leads to a significant viscosity reduction in high-temperature environments, ${ }^{19,20}$ which limits the proppant transportation capability severely. ${ }^{21,22}$ To obtain the effective transport of proppant at high temperatures, a high dosage (usually 3-5 wt \%) of surfactant is generally required in $\mathrm{VES},{ }^{23-26}$ which results in the high cost for the immense surfactant consumption and restricts the extensive application of VES fracturing fluids. ${ }^{6}$ Therefore, it is necessary to develop novel VES fracturing fluids with low surfactant concentrations that have the favorable performance at high temperatures.

Since the first application of VES fracturing fluid by Schlumberger with cationic single-chain surfactant in $1997,{ }^{27}$

Received: November 8, 2020

Accepted: December 29, 2020

Published: January 8, 2021 


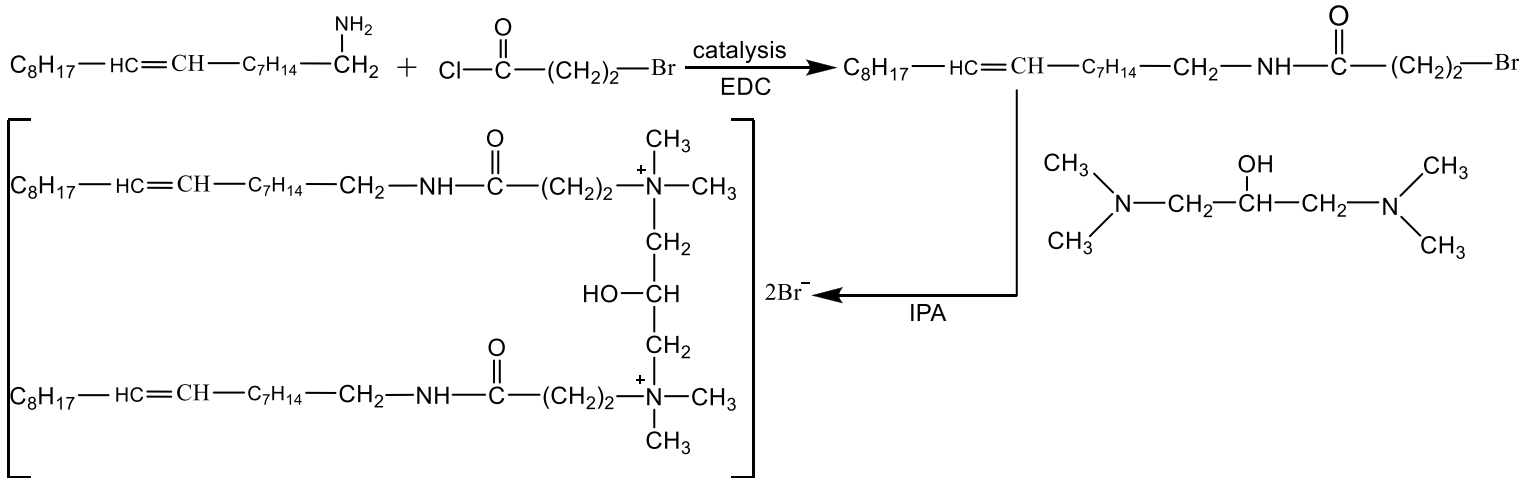

Figure 1. Structure and synthetic route of GLO.

most of the VES fluids were prepared with single-chain surfactants. ${ }^{28,29}$ Because there is a sole hydrophobic tail linked to a hydrophilic head, the single-chain surfactants could not associate into micelles readily for the electrostatic repulsion among the charged hydrophilic groups. ${ }^{30}$ Compared to the conventional single-chain surfactants, gemini surfactants, ${ }^{31,32}$ a class of superior surfactants comprising two amphiphilic moieties linked by a spacer group, could satisfy the request of proppant transportation for fracturing fluid more easily. ${ }^{15,26}$ There are better reductions of flow resistance ${ }^{33}$ and heat/ shear resistance ${ }^{34,35}$ in the VES fracturing fluid prepared with gemini cationic surfactants. The contour length of micelles proposed by Magid ${ }^{36}$ is a crucial parameter positive to the micellar morphology ${ }^{36}$ and the capability of proppant transportation, following eq $1:^{37}$

$$
L \simeq \phi^{1 / 2} \exp \left[E_{\mathrm{c}} /(2 k T)\right]
$$

where $L$ is the contour length of micelles, $\phi$ is the volume fraction of surfactant, $E_{\mathrm{c}}$ is the end-cap energy of micelles, $k$ is the rate constant, and $T$ is the absolute temperature. Current research indicated that the long, unsaturated hydrophobic tails led to the increase of end-cap energy, ${ }^{38}$ resulting in the enhancement of the contour length of micelles. Mao et al. ${ }^{39}$ proposed that the end cap could increase as the volume occupied by the hydrophobic tail increases due to the kink of the cis double bond in the tails. The researches of Zhang et al. $^{24}$ and Yang et al. ${ }^{40}$ reported that the VESs exhibited good properties with the hydrophobic chains about C22. Rose and Foster $^{41}$ stated that the presence of the surfactant with unsaturated tails resulted in the reduction of drag. Consequently, the load of the pumps during fracturing could be decreased. ${ }^{42}$ In addition, the length of the spacer group affects the critical micelle concentration (CMC), critical surface tension, and salt resistance significantly. Mao et al. ${ }^{39}$ indicated that the wormlike micelles could be generated easily by the gemini surfactants with a spacer of $\mathrm{C} 3$, resulting in excellent viscoelasticity. Wei et al. ${ }^{43}$ claimed that the hydroxyl group on the spacer group could generate hydrogen bonds with water molecules in the aqueous solution and reduce the electrostatic repulsion between the ionic head groups. ${ }^{43}$ Moreover, the amide-containing surfactant is biodegradable due to the enzymatic hydrolysis through environmental microorganism actions. ${ }^{44-46}$

Inspired by the above recognition, cationic gemini surfactants with the abovementioned advantages show a favorable potential to be used for VES fracturing fluid at low concentration theoretically. To the best of our knowledge, there is very little research on this topic. Herein, a novel cationic gemini surfactant (GLO) was prepared, which consists of two long tails of $\mathrm{C} 21$ containing olefinic and amide, and a spacer of $\mathrm{C} 3$ containing a hydroxyl group. Furthermore, the behaviors of the VES fracturing fluid containing 2.0 wt \% of GLO was characterized by different experiments. It was demonstrated that the novel VES fluid offers a promising material to satisfy the fracturing process.

\section{EXPERIMENTS}

2.1. Materials. Tallow alkyl (99\%) and 1,3-bis (dimethylamino) propan-2-ol (99\%) were supported by Hubei Xinkang Pharmaceutical Chemical Co., Ltd. 1,2-Dichloroethane (EDC, 99,9\%) and 4-dimethylaminopyridine (DMAP, 99\%) were purchased from Shanghai Aladdin Biochemical Technology Co., Ltd. Isopropanol (IPA), ethyl alcohol (EtOH), ethyl acetate (EAC), potassium chloride $(\mathrm{KCl})$, and sodium salicylate (NaSal), AR, were obtained from Sinopharm Chemical Reagent Co., Ltd. 3-Bromopropanoyl chloride (95.0\%) was supplied from Bailingwei Science and Technology Co., Ltd. LWP3050 proppant and aviation kerosene were purchased from Tianhong proppants Co., Ltd. and Jinan Xinquan Chemical Technology Co., Ltd. respectively. The deionized water (DI water) was prepared in the lab, while natural core samples, formation water $\left(\mathrm{CaCl}_{2}\right.$, salinity 17,000 $\mathrm{mg} / \mathrm{L}$, density $1.01 \mathrm{~g} / \mathrm{cm}^{3}$, viscosity $1.38 \mathrm{mPa} \cdot \mathrm{s}$ at $18{ }^{\circ} \mathrm{C}$ ), and crude oil were acquired from Huangling Chang 6 tight oil formation, Ordos Basin, China. The simulated crude oil (density $0.83 \mathrm{~g} / \mathrm{cm}^{3}$, viscosity $2.88 \mathrm{mPa} \cdot \mathrm{s}$ at $18{ }^{\circ} \mathrm{C}$ ) was prepared by mixing the kerosene and the crude oil at a volume ratio of $3: 1$.

2.2. Synthesis of GLO. The steps of the synthesis were as follows.

2.2.1. Synthesis of 3-bromo-N-(octadec-9-en-1-yl) propenamide. First, tallow alkyl $(0.2 \mathrm{~mol})$ was dissolved with EDC $(300 \mathrm{~mL})$. Then, 3-bromopropanoyl chloride $(0.25 \mathrm{~mol})$ was diluted with EDC $(100 \mathrm{~mL})$ and dripped into the threenecked flask containing the solution of tallow alkyl slowly under stirring. The speed of dripping should be low enough to control the temperature of the solution in the flask lower than $40{ }^{\circ} \mathrm{C}$. DMAP with a concentration of 0.4 wt $\%$ was used as the catalyst. The mixture was kept under stirring $(150 \mathrm{rpm})$ for $2 \mathrm{~h}$ in a magnetic stirring water bath (HWX-15A, Shanghai Jinwen Instrument Equipment Co., Ltd.). Finally, the solvent and the excess 3-bromopropanoyl chloride were distilled at 90 ${ }^{\circ} \mathrm{C}$ with a rotary evaporator (RE-52AA, Shanghai Yarong Biochemical Instrument Factory). 
2.2.2. Synthesis of GLO. Initially, 3-bromo- $N$-(octadec-9en-1-yl) propanamide $(0.25 \mathrm{~mol})$ and 3-bis (dimethylamino) propan-2-ol $(0.1 \mathrm{~mol})$ were added into the flask containing IPA $(400 \mathrm{~mL})$. The mixture was then stirred for $6 \mathrm{~h}$ at $60{ }^{\circ} \mathrm{C}$ followed by the removal of the solvent with the rotary evaporator at $60{ }^{\circ} \mathrm{C}$. The product was recrystallized twice with the mixed solvent of EAC and $\mathrm{EtOH}$ (volume ratio 20:1). It was then dried at $80{ }^{\circ} \mathrm{C}$ for $24 \mathrm{~h}$ in a vacuum drying oven (Shanghai Lichenbangxi Instrument Technology Co., Ltd.). The structure of the novel gemini surfactant and its synthetic route were designed as shown in Figure 1.

2.3. Molecular Structure Characterizations of GLO. The molecular structure of GLO was obtained with Fourier infrared spectrometry (FT-IR, VERTEX 70, Brukeroptics, Germany), nuclear magnetic resonance spectrometry $\left({ }^{1} \mathrm{H}\right.$ NMR, ${ }^{13} \mathrm{C}$ NMR, DD2-500MH, Agilent Technologies Inc., USA), and high-resolution mass spectrometry (HRMS, LTQ Orbitrap XL, Thermo Fisher, USA).

2.4. Test of GLO-based VES Fracturing Fluid. 2.4.1. Formation of the GLO-based VES Fracturing Fluid. $\mathrm{KCl}$ was used as the clay stabilizer with a dosage of $1.0 \mathrm{wt} \%$ here. There are few $\mathrm{Cl}^{-}$counterions ionized from $\mathrm{KCl}$ that could penetrate the aggregate of surfactant, while the counterions ionized from $\mathrm{NaSal}$ could insert between the charged headgroups of the surfactant to screen the electrostatic repulsions and promote the growth of micelles. ${ }^{47}$ Therefore, NaSal was used as the counterion salt here. The concentrations of GLO and NaSal were optimized based on the viscosity measured with a rheometer (DV3T, Brookfield, USA) according to the Chinese industrial standard SY/T 5107-2016. Unless otherwise specified, all experiments were conducted under a room temperature of $18{ }^{\circ} \mathrm{C}$, and the same applies below.

2.4.2. Test of Heat/Shear Resistance. The heat/shear resistance measurements were carried out by a rheometer(MCR 302, Anton Paar, USA) with the measuring system of CC27 (coaxial cylinder) according to the Chinese industrial standard SY/T 5107-2016. The temperature ranged from 18 to $80{ }^{\circ} \mathrm{C}$ (the original temperature of the tight reservoir where the core samples were collected from) with a heating rate of 3 ${ }^{\circ} \mathrm{C} / \mathrm{min}$. The shear rate during the experiment was kept at $170 \mathrm{~s}^{-1}$ for $2 \mathrm{~h}$.

2.4.3. Test of Rheological Properties. The rheological properties of the VES fracturing fluid were also tested on the rheometer (MCR 302, Anton Paar, USA) according to the Chinese industrial standards SY/T 5107-2016 and SY/T 6296-2013. The stress-shear rate curve was measured in a shear rate range of $0.01 \sim 1000 \mathrm{~s}^{-1}$ with the measuring system of $\mathrm{CC} 27$ on the rheometer. The modulus was measured with the measuring system of PP50-1 (plane plate) under the frequency sweep mode ranging from 0.1 to $100 \mathrm{rad} / \mathrm{s}$ with constant stress in the linear viscoelastic region.

2.4.4. Test of Proppant Transportation Carried by GLObased VES Fracturing Fluid. Proppant distribution is a curial criterion to evaluate the fracturing operations. ${ }^{48,49}$ Herein, dynamic proppant transportation carried by GLO-based VES fracturing fluid was evaluated with the simulated vertical crack shown in Figure 2. The length, width, and height of the simulated crack were $100,0.15$, and $20 \mathrm{~cm}$ respectively. There were four viewing windows arranged along the flow direction in the crack. The proppant (mesh size 30-50; apparent density $3.0 \mathrm{~g} / \mathrm{cm}^{3}$ ) was used with a concentration of $30 \mathrm{wt} \%$. The proppant carried VES fracturing fluid was injected from

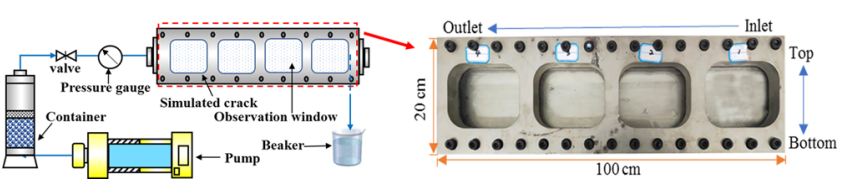

Figure 2. Schematic of the dynamic proppant transportation test.

the inlet at a constant velocity of $5 \mathrm{~mL} / \mathrm{min}$ for $2 \mathrm{~h}$ and overflown into the beaker from the outlet when the crack was stuffed.

2.4.5. Evaluation of Formation Damage Caused by GLObased VES Fracturing Fluid. Matrix permeability damage: The measurements of the matrix permeability damage were conducted according to the Chinese industrial standard of SY/T 5107-2016 with the fracturing fluid filtrate on the core displacement device (Haian Petroleum Scientific Research Instrument Co., Ltd.). First, the core was saturated with formation water and then displaced with simulated crude oil from the inlet of the core container to get the oil-saturated cores containing irreducible water and the initial oil permeability $\left(K_{1}\right)$ of the cores. Afterward, the fracturing fluid filtrate was injected into the core container for $36 \mathrm{~min}$ from the other end to simulate the procedure of matrix damage. The core container was shut in for $2 \mathrm{~h}$ after injecting the fracturing fluid filtrate. The simulated crude oil was then re-injected into the core from the inlet to get the matrix permeability after damage $\left(K_{2}\right)$. The injection velocity during the test was invariably kept at $0.2 \mathrm{~mL} / \mathrm{min}$. The permeability loss rate $(\eta)$ is defined as eq 2 . The parameters of the core samples used in the test are listed in Table S1.

$$
\eta=\frac{K_{1}-K_{2}}{K_{1}} \times 100 \%
$$

Crack conductivity damage: The cores were cracked, propped up with $\Phi 0.5 \mathrm{~mm}$ copper, and sealed (except the surface of cracks, shown in Figure S1) in turn to simulate the cracks used in the experiments. The simulated crude oil was injected into the core container first to obtain the initial conductivity of the cracks. After that, $100 \mathrm{~mL}$ of the fracturing fluid was injected into the core container with a back pressure of $5 \mathrm{MPa}$. The container was then shut in for $2 \mathrm{~h}$ to simulate the leak off of the fracturing fluid and the generation of the filter cake. Finally, simulated crude oil was re-injected to obtain the conductivity after damage. The velocity of injection during the whole test was invariably kept at $5 \mathrm{~mL} / \mathrm{min}$. The parameters of the simulated cracks are listed in Table S2.

\section{RESULT AND DISCUSSION}

3.1. Molecular Structure. The ${ }^{1} \mathrm{H}$ NMR $\left(\mathrm{CD}_{4} \mathrm{O}, 499 \mathrm{~Hz}\right.$, $\delta$ ) spectra were studied to confirm the formation of the product (Figure 3). The peaks at $\delta 0.89(6 \mathrm{H}, \mathrm{a}-\mathrm{H})$ for $\mathrm{H}$ corresponded to the $-\mathrm{CH}_{3}$ at the end of the hydrophobic chains. The peaks at $\delta 1.30(48 \mathrm{H}, \mathrm{b}-\mathrm{H})$ for $\mathrm{H}$ lay in methylene $-\left(\mathrm{CH}_{2}\right)_{6}-$ of the tallow alkyl. The peaks at $\delta 2.04$ $(8 \mathrm{H}, \mathrm{c}-\mathrm{H})$ for $\mathrm{H}$ corresponded to the methylene linked to the olefinic bonds $-\mathrm{CH}_{2}-\mathrm{CH}=\mathrm{CH}-\mathrm{CH}_{2}-$. The peaks around $\delta$ $2.56(4 \mathrm{H}, \mathrm{d}-\mathrm{H})$ and $\delta 3.52(4 \mathrm{H}, \mathrm{h}-\mathrm{H})$ were generated by the $\mathrm{H}$ in the methylene linked to the carbon of acylamino $-\mathrm{CH}_{2}-\mathrm{CH}_{2}-\mathrm{CO}-\mathrm{NH}-\mathrm{CH}_{2}-$ and the $\mathrm{H}$ in the methylene linked to the nitrogen of quaternary ammonium $-\mathrm{N}\left(\mathrm{CH}_{3}\right)_{2}-$ $\mathrm{CH}_{2}-\mathrm{CH}_{2}-\mathrm{CO}-\mathrm{NH}-$, respectively. The peaks of $\delta 3.01$ $(4 \mathrm{H}, \mathrm{e}-\mathrm{H})$ and $\delta 7.75(2 \mathrm{H}, \mathrm{l}-\mathrm{H})$ were the $\mathrm{H}$ on the acylamino 


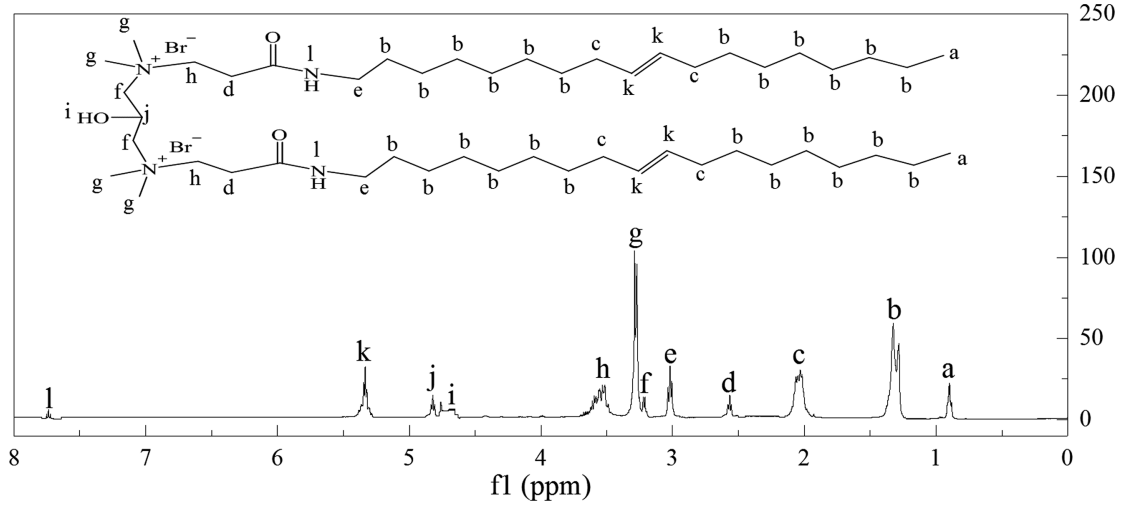

Figure 3. ${ }^{1} \mathrm{H}$ NMR spectra of the production.

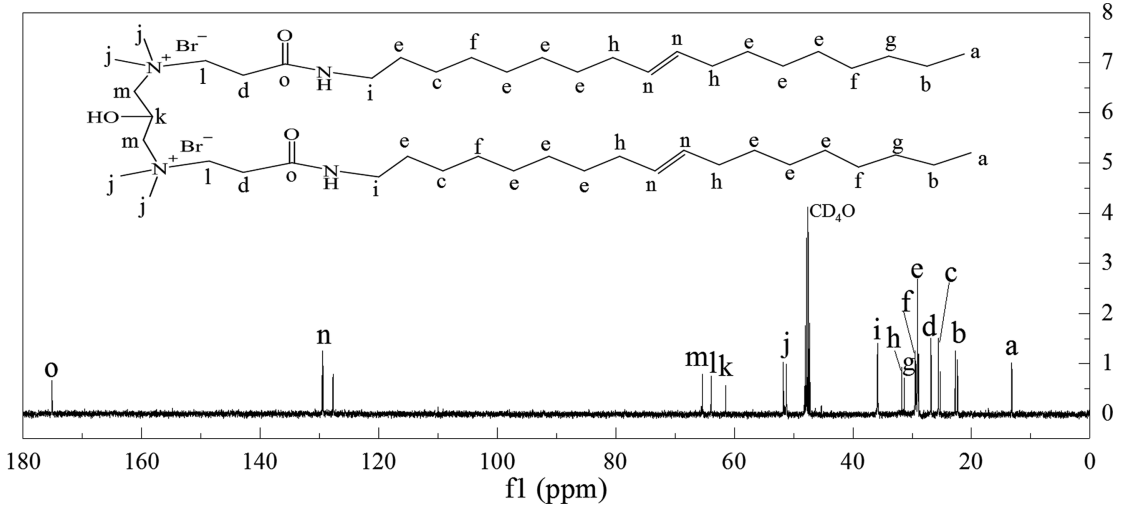

Figure 4. ${ }^{13} \mathrm{C}$ NMR spectra of the production.

- $\mathrm{CO}-\mathrm{NH}-\mathrm{CH}_{2}-$ and methylene linked to the acylamino $-\mathrm{CO}-\mathrm{NH}-\mathrm{CH}_{2}-\mathrm{CH}_{2}-$, respectively. The peaks of $\delta 3.21$ $(4 \mathrm{H}, \mathrm{f}-\mathrm{H})$ and $\delta 3.29(12 \mathrm{H}, \mathrm{g}-\mathrm{H})$ occurred in the methylene of the spacer group $-\mathrm{N}\left(\mathrm{CH}_{3}\right)_{2}-\mathrm{CH}_{2}-\mathrm{CHOH}-$ and the methyl $-\mathrm{CH}_{2}-\mathrm{N}\left(\mathrm{CH}_{3}\right)_{2}-\mathrm{CH}_{2}-$ of the quaternary ammonium, respectively. The peaks around $\delta 4.67(1 \mathrm{H}, \mathrm{i}-\mathrm{H})$ and $\delta$ $4.81(1 \mathrm{H}, \mathrm{j}-\mathrm{H})$ were generated in the hydroxyl $-\mathrm{CH}_{2}-$ $\mathrm{CHOH}-\mathrm{CH}_{2}-$ and methine $-\mathrm{CH}_{2}-\mathrm{CHOH}-\mathrm{CH}_{2}-$ of the spacer group, respectively. The peaks around $\delta 5.33(4 \mathrm{H}, \mathrm{k}-$ $\mathrm{H}$ ) corresponded to the $\mathrm{H}$ in the olefinic bonds $-\mathrm{CH}_{2}-$ $\mathrm{CH}=\mathrm{CH}-\mathrm{CH}_{2}-$.

The ${ }^{13} \mathrm{C}$ NMR $\left(\mathrm{CD}_{4} \mathrm{O}, 126 \mathrm{~Hz}, \delta\right)$ spectra of the product are shown in Figure 4. The chemical shift of ${ }^{13} \mathrm{C}$ NMR corresponded with ${ }^{1} \mathrm{H}$ NMR well. Based on the information obtained from the spectra of ${ }^{1} \mathrm{H}$ NMR, we further studied the key data of ${ }^{13} \mathrm{C}$ NMR during the synthesis of GLO. The peak of $\delta 35.92$ (i-C) was the $\mathrm{C}$ in methylene linked to the acylamino $-\mathrm{CH}_{2}-\mathrm{CO}-\mathrm{NH}-\mathrm{CH}_{2}-\mathrm{CH}_{2}-$, while the peak of $\delta 175.24$ (o-C) occurred in the carbonyl group of the acylamino $-\mathrm{CH}_{2}-\mathrm{CO}-\mathrm{NH}-\mathrm{CH}_{2}-$. The peaks at $\delta 63.86$ (1C) and $\delta 65.33(\mathrm{~m}-\mathrm{C})$ corresponded to the methylene linked to the quaternary ammonium from the spacer group ( $\left.-\mathrm{CHOH}-\mathrm{CH}_{2}-\mathrm{N}\left(\mathrm{CH}_{3}\right)_{2}-\mathrm{CH}_{2}-\mathrm{CH}_{2}-\right)$ and the tail chain $\left(-\mathrm{CHOH}-\mathrm{CH}_{2}-\mathrm{N}\left(\mathrm{CH}_{3}\right)_{2}-\mathrm{CH}_{2}-\mathrm{CH}_{2}-\right)$, respectively.

The spectra of FT-IR are shown in Figure 5. The adsorption peaks at 3280 and $1036 \mathrm{~cm}^{-1}$ corresponded to the stretching vibration of $\mathrm{O}-\mathrm{H}$ and $\mathrm{C}-\mathrm{O}$ on the hydroxy group, respectively. The adsorption peak at $3032 \mathrm{~cm}^{-1}$ indicated the stretching vibration of $=\mathrm{CH}-$. The adsorption peaks at 2926, 2851, and $1460 \mathrm{~cm}^{-1}$ represented the asymmetric stretching vibration, the symmetric vibration,

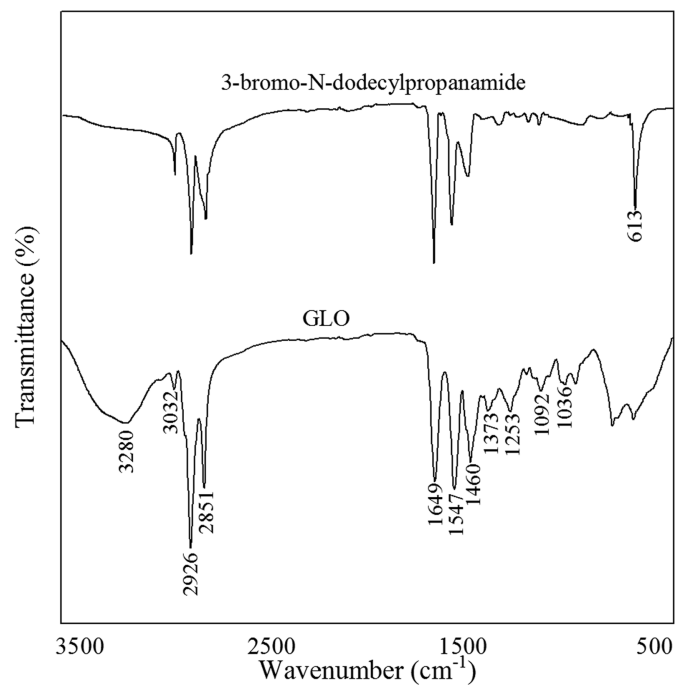

Figure 5. Infrared spectra of the intermediate and the production.

and the bending vibration of $-\mathrm{CH}_{2}-$, respectively. The adsorption peaks at $1649,1547,1253$, and $1092 \mathrm{~cm}^{-1}$ showed the stretching vibration of $\mathrm{C}=\mathrm{O}$, the bending vibration of $\mathrm{N}-\mathrm{H}$, the bending vibration of $-\mathrm{CONH}-$, and the stretching vibration of $\mathrm{C}-\mathrm{N}$ on the secondary amide group, respectively. The adsorption peak at $1373 \mathrm{~cm}^{-1}$ expressed the bending vibration of $-\mathrm{CH}_{3}$. The quaternization could be deduced from the weakened adsorption peak at $613 \mathrm{~cm}^{-1}$, which inferred the decrease of the $\mathrm{C}-\mathrm{Br}$ bond.

Figure 6 demonstrates the HRMS (Fourier transform ion cyclotron resonance MS, FT-MS; electrospray ionization, ESI) 


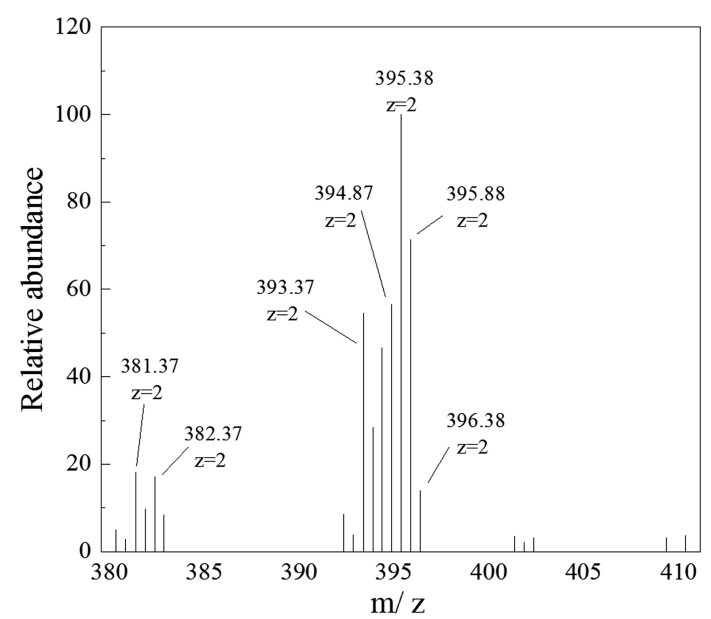

Figure 6. HRMS spectra of the production.

spectra of the product. $[\mathrm{M}]^{2+}$ calculated for $\left[\mathrm{C}_{49} \mathrm{H}_{98} \mathrm{~N}_{4} \mathrm{O}_{3}\right]^{2+}=$ 395.38 was found at the highest peak. As supported by the molecular structure analysis of FT-IR, ${ }^{1} \mathrm{H}$ NMR, ${ }^{13} \mathrm{C}$ NMR, and HRMS, it could be confirmed that the designed gemini surfactant GLO was produced.

3.2. VES Fracturing Fluid Formulation. The viscosities of the VES fluid prepared with different concentrations of GLO were studied. Due to the phase separation, the records at the points such as the concentration of NaSal higher than 0.3 wt $\%$ under the condition of 0.5 wt $\%$ GLO were sifted out, which were removed from the results. As shown in Figure 7 , when the concentration of GLO was lower than $2.0 \mathrm{wt} \%$,

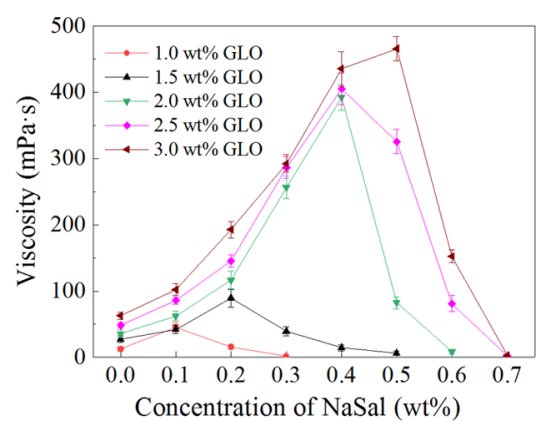

Figure 7. Viscosity under different formulations (1.0 wt \% $\mathrm{KCl}$ was used here as the clay stabilizer). Error bar $=\operatorname{RSD}(n=3)$.

the viscosity increased dramatically with the increase of GLO concentration. However, the increase became slightly equilibrium when the dosage of GLO concentration was higher than 2.0 wt \%. Because NaSal provides the counterions for the surfactant aggregate, the viscosity of the VES fluid was greatly affected by the concentration of $\mathrm{NaSal}^{38}$ The viscosity increased significantly in the region of low NaSal concentration before reaching the threshold points, while decreased rapidly under the high concentration of $\mathrm{NaSal}$.

According to the theory proposed by Israelachvili, ${ }^{50}$ the viscosity of the VES fluid depends on the architecture of the surfactant aggregate, which could be predicted by the packing parameter $p$ defined as:

$$
p=\frac{V}{A l}
$$

where $V$ is the volume of the surfactant tail, $A$ is the effective area of per surfactant hydrophilic head at the aggregate surface, $l$ is the length of the surfactant tail in the solvent. When $p$ increased from less than $1 / 3$ to about $1 / 2$, the surfactant molecules assemble in different shapes from sphere to wormlike micelle. ${ }^{51}$ Keeping $p$ increasing led to the aggregate of surfactant and the formation of vesicles $(1 / 2<p$ $<1)$ which finally separated from the rest of the solution $(p>$ 1). As shown in Figure 8, a large volume and short length of

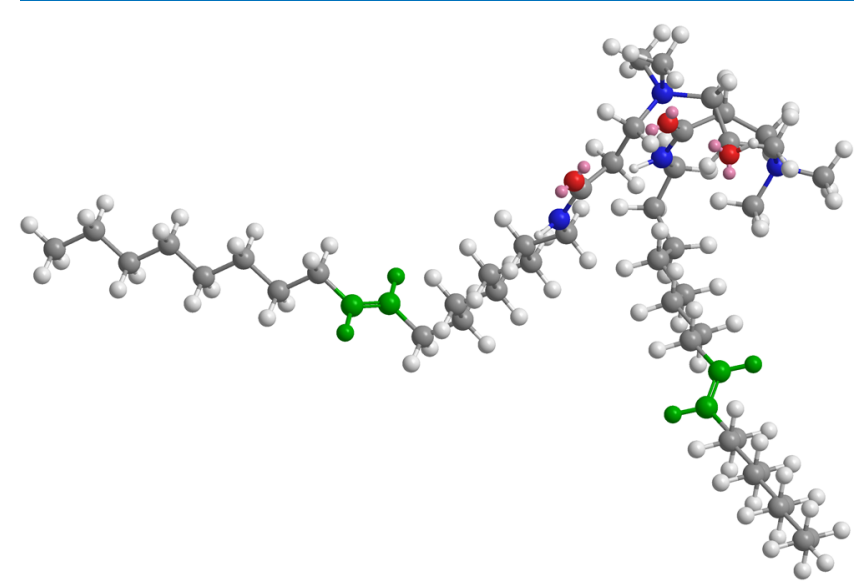

Figure 8. 3D structure of GLO.

the tails were obtained in GLO by the long hydrophobic chains bending adjacent to the double bonds (the green segment in Figure 8). On the other hand, the counterions from $\mathrm{NaSal}$ reduced the electrostatic repulsion between the charged hydrophilic head, which compressed the effective area of the hydrophilic head and led to a tighter network based on increased wormlike micellar aggregations. With a combination of the above effects, GLO realized a high viscosity even at a low concentration with a proper dosage of $\mathrm{NaSal}$. With the continual increase of counterion concentration, the short distance between surfactant molecules resulting from the exceeded counterions led to precipitates of the surfactant from the solution as a nonionic molecule. ${ }^{52}$ As a result, the phase separation occurred inevitably, and the viscosity of the fluid drops.

With a view to the combination of viscosity and the cost, the formula of $2.0 \mathrm{wt} \% \mathrm{GLO}+0.4 \mathrm{wt} \% \mathrm{NaSal}+1.0 \% \mathrm{KCl}$ was most promising (the viscosity corresponding to this formula was $392.4 \mathrm{mPa} \cdot \mathrm{s}$ at $18{ }^{\circ} \mathrm{C}$ ) for the VES fracturing fluid, which was employed in the following studies.

3.3. Heat/Shear Resistance. The result of the heat/shear resistance measurement for the VES fracturing fluid is presented in Figure 9. The viscosity of the VES fracturing fluid decreased from 405.5 to $98.7 \mathrm{mPa} \cdot \mathrm{s}$ as the temperature increased from 18 to $80{ }^{\circ} \mathrm{C}$ and became equilibrium at about $70.2 \mathrm{mPa} \cdot \mathrm{s}$. To reveal this phenomenon, the microstructures of the VES fracturing fluid before and after the temperature change were characterized by the high-resolution mass spectrometer scanning electron microscopy (SEM, S4800, Hitachi, Japan). The samples were prepared by coating the quartz slice with the fluid droplets and then drying it at 18 and $80{ }^{\circ} \mathrm{C}$, respectively. The results of SEM are shown in Figure 10. It was found that the microstructure of the VES at $18^{\circ} \mathrm{C}$ was very tight and homogenously distributed, which got extruded and re-assembled owing to the fierce molecule 


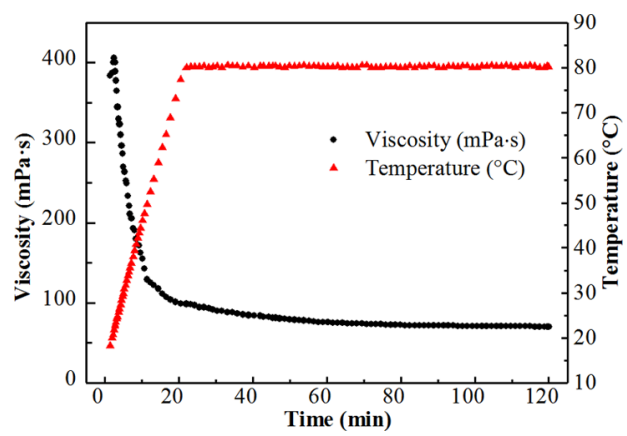

Figure 9. Curves of heat/shear resistance.

thermal motion at $80{ }^{\circ} \mathrm{C}$. Thanks to the special structure of GLO, there was an evident packing in the VES fracturing fluid even at $80{ }^{\circ} \mathrm{C}^{36,38}$

3.4. Rheological Property. The stress-shear rate curve of the VES fracturing fluid is shown in Figure 11a. The rheological parameters of non-Newtonian fluid are usually studied with the Herschel-Bulkley equation: ${ }^{53}$

$$
\tau=\tau_{0}+K \cdot \gamma^{n}
$$

where $\tau$ is the shear stress, Pa; $\tau_{0}$ is the yield stress, Pa; $K$ is the consistency coefficient, $\mathrm{mPa} \cdot \mathrm{s}^{n} ; \gamma$ is the shear rate, $\mathrm{s}^{-1}$; and $n$ is the flow behavior index. The fluid type of the VES fracturing fluid was obtained by fitting its stress-shear rate curve with eq 4 , and the result is presented in eq 5 . The fracturing was a typical pseudoplastic fluid for the flow behavior index was lower than 1 .

$$
\tau=0.5+8.7 \times \gamma^{0.18}
$$

The viscoelasticity was measured under the mode of frequency scanning with a constant shear stress of $1.0 \mathrm{~Pa}$ in the linear viscoelastic region (the region was determined by Figure S3). As shown in Figure 11b, the elastic modulus $G^{\prime}$ (storage modulus) was always higher than the viscous modulus $G^{\prime \prime}$ (loss modulus) during the whole test. It indicated that the fracturing fluid exhibited typical elastic material characteristics. To conclude, the VES fracturing fluid was a typical elastic pseudoplastic fluid with a yield stress of 0.5 Pa.

3.5. Proppant Transportation Carried by GLO-based VES Fracturing Fluid. The proppant transportation capability was demonstrated by studying the distribution of the proppant in the crack after the injection (Figure 12). A uniform proppant distribution was observed here. The statistics of the proppant mass collected from the different segments of the crack are listed in Table 1 . The difference of the proppant mass proportion among the four segments was no more than $4.3 \%$, indicating that the proppant was homogenously carried by the VES fracturing fluid during the injection.

The dynamic setting velocity of proppant is defined in eq 6:

$$
v=\frac{\Delta M}{T}=\frac{M_{\mathrm{c}}-M}{T}
$$

where $v$ is the proppant setting velocity, $\mathrm{g} / \mathrm{min} ; \Delta M$ is the mass of the proppant setting in each segment during the proppant transport, $g ; T$ is the time of setting/transport, which was $120 \mathrm{~min} ; M_{\mathrm{c}}$ is the mass of the proppant collected from each segment, g; $M$ is the mass of the proppant suspended in the fluid filling each segment of the crack, g, which could be obtained from the following eq 7 :

$$
M=V \times \rho \times C=W \times L / 4 \times H \times \rho \times C
$$

where $V$ is the volume of each segment, $\mathrm{cm}^{3} ; \rho$ is the density of the sand-carrying fluid, $\mathrm{g} / \mathrm{cm}^{3} ; C$ is the mass concentration of the proppant suspended in the fluid, wt \%; $W, L$, and $H$ are the width, length, and height of the simulated crack, respectively, in $\mathrm{cm}$. The proppant settling velocities in different segments are also listed in Table 1 . The proppant was setting at a very low velocity ranging from $0.06 \mathrm{~g} / \mathrm{min}$ (in segment 1) to $0.12 \mathrm{~g} / \mathrm{min}$ (in segment 4 ) with an average value of $0.08 \mathrm{~g} / \mathrm{min}$ along the simulated crack. The difference of the proppant setting velocity among these segments resulted from the difference of the fluid flow velocity along the crack. Because the inlet and outlet were placed at the upper right corner of segment 1 and the upper left corner of segment 4 , respectively, there was a low-velocity zone observed at the bottom of segment 3 and segment 4 (shown in the green ellipse of Figure 12). As a result, the proppant setting velocity in this zone was higher.

3.6. Formation Damage. The results of the matrix damage tests are shown in Figure 13. The permeability loss rates of the four natural cores lay in $9.0-11.6 \%$. The average value of the permeability loss rates was $10.4 \%$.

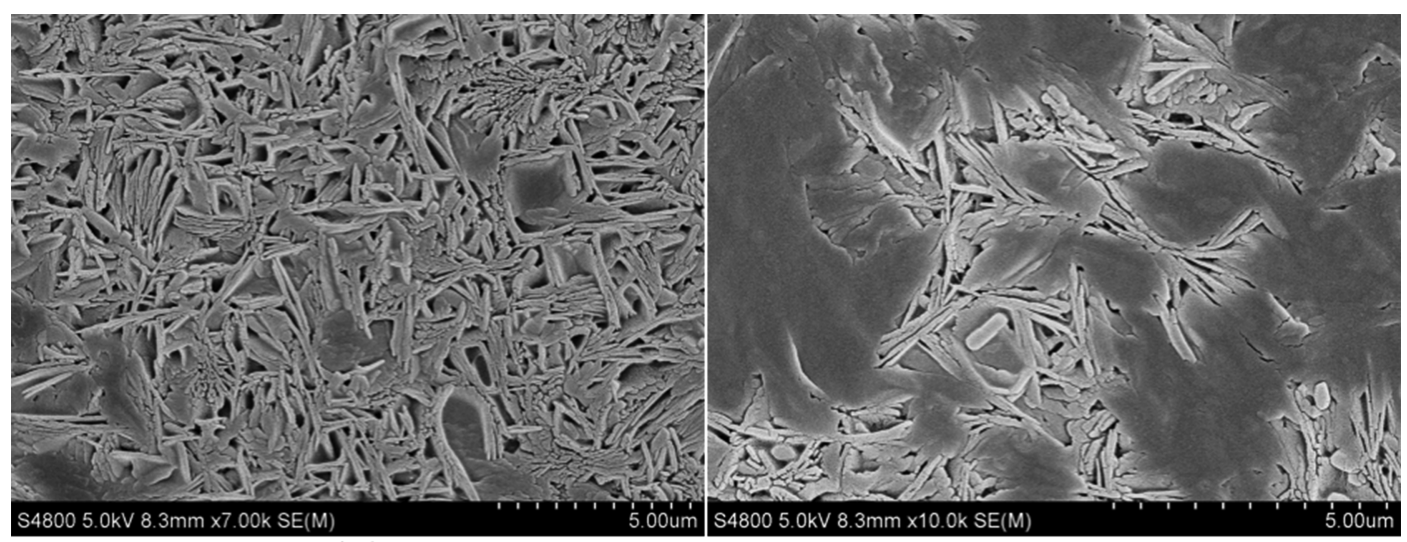

(a)

(b)

Figure 10. SEM photos of VES fracturing fluid (a) before the measurement and (b) after the measurement. 


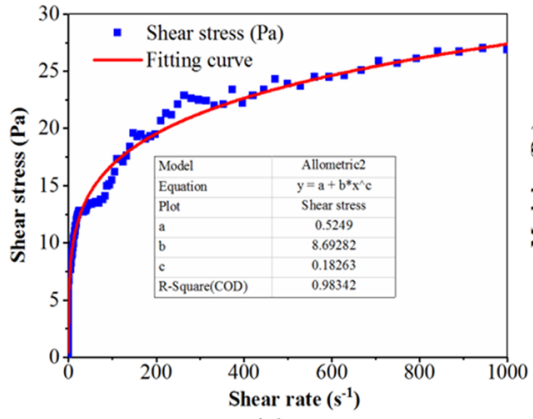

(a)

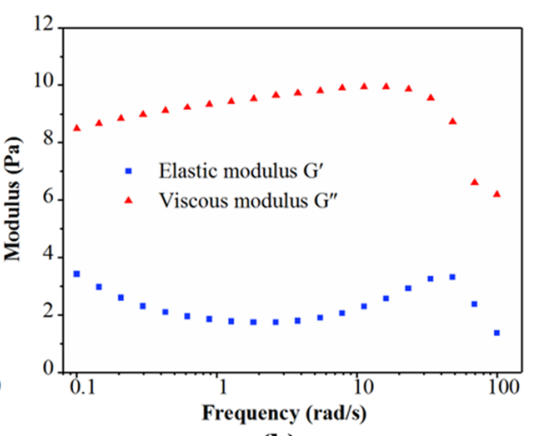

(b)

Figure 11. Rheological curves of the VES fracturing fluid. (a) Stress-shear rate curve and (b) the measurement of the viscoelasticity.

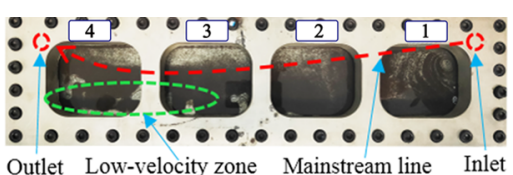

Figure 12. Dynamic proppant distribution.

Table 1. Statistics of the Proppant Collected from Different Segments

\begin{tabular}{lcccc}
\multicolumn{1}{c}{ segments } & $\begin{array}{c}\text { window 1 } \\
\text { (inlet) }\end{array}$ & window 2 & window 3 & $\begin{array}{c}\text { window 4 } \\
\text { (outlet) }\end{array}$ \\
$\begin{array}{l}\text { proppant mass (g) } \\
\text { mass Proportion } \\
\text { (\%) }\end{array}$ & 41.8 & 42.5 & 45.2 & 49.5 \\
$\begin{array}{c}\text { setting velocity } \\
\text { (g/min) }\end{array}$ & 23.4 & 23.7 & 25.3 & 27.7 \\
\hline
\end{tabular}

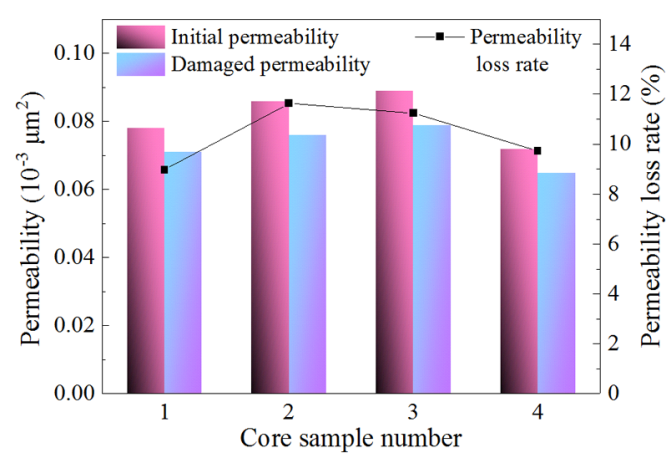

Figure 13. Matrix permeability damage.

The VES fracturing fluid comprised no insoluble components that would bring about the blocking in the matrix. Therefore, the damage just depended on the properties of the interface between the liquids and channel surface. The contact angles (CAs) of the formation water and fracturing fluid filtrate on the core slices and the interfacial tensions (IFTs) of simulated crude oil/formation water and simulated crude oil/filtrate were measured. As shown in Figure 14, affected by the surfactant GLO, the CA of the filtrate decreased from 56.2 to $45.4^{\circ}$ and the IFT between oil and the filtrate decreased from 19.5 to $1.6 \mathrm{mN} / \mathrm{m}$ compared to the formation water. It means that the drag on the oil flow and the water lock effect, a phenomenon closely related to the interfacial tension (IFT), were reduced. As a result, the VES fluid showed little damage to matrix permeability caused by the invaded filtrate.

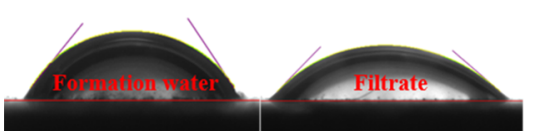

(a)

(b)

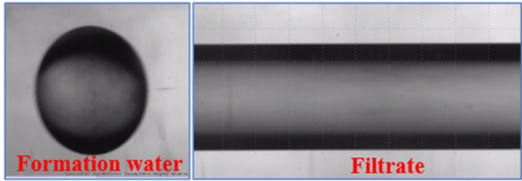

(c)

(d)

Figure 14. Photos of CAs and IFTs. (a) CA of formation water, (b) CA of the filtrate, (c) IFT between simulated crude oil and formation water, and (d) IFT between simulated crude oil and filtrate.

The results of the conductivity damage measurements in the simulated cracks are shown in Figure 15. The conductivity loss rates of the four simulated cracks ranged from 4.0 to $6.4 \%$ with an average value as low as $5.4 \%$.

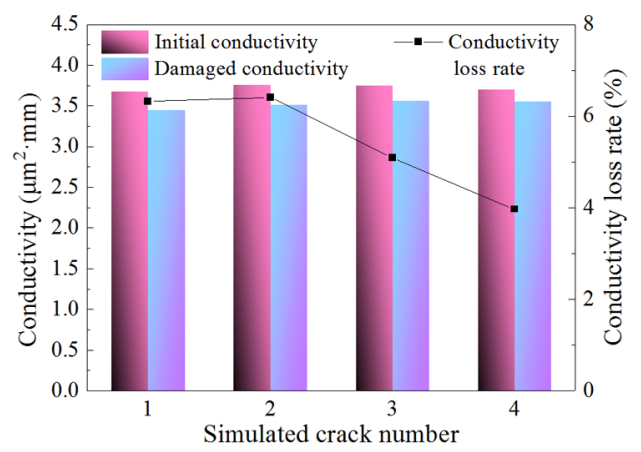

Figure 15. Crack conductivity damage.

As the analysis in section 2.2, VES fluid showed great differences in viscosity due to the different forms of surfactant aggregate. $^{39}$ In the presence of salicylate counterions, the injected VES fracturing fluid was in a surfactant aggregate of entangled wormlike micelles at the beginning. When the simulated crude oil was injected into the cracks, the surfactant molecules would migrate to the interface of the oil droplets/ water to solubilize the oil phase. Consequently, the entangled micellar network was destroyed into dispersed small aggregates around the oil droplets. In other words, the VES fluid could be broken by the crude oil. That was why the conductivity of the crack was damaged slightly by the VES fracturing fluid. 


\section{CONCLUSIONS}

A novel gemini surfactant GLO with long tails and double bonds was synthesized as the low-concentration thickener of VES fracturing fluid. A series of experiments were conducted to ascertain the structure of the product and evaluate the properties of the VES fracturing fluid. The following conclusions could be drawn:

(1) The results of molecular structure characterizations confirmed that the designed gemini surfactant (GLO) containing long tail and double bonds was produced. Moreover, the formula of $2.0 \mathrm{wt} \% \mathrm{GLO}+0.4 \mathrm{wt} \%$ $\mathrm{NaSal}+1.0$ wt \% $\mathrm{KCl}$ for the VES fracturing fluid was optimized. Different from the previous researches, ${ }^{15,39}$ the dosage of surfactant decreased significantly.

(2) The VES fracturing fluid showed a high viscosity of $392.4 \mathrm{mPa} \cdot \mathrm{s}$ at $18{ }^{\circ} \mathrm{C}$ and the desired property of heat/ shear resistance. The viscosity kept as high as $70.2 \mathrm{mPa}$. $\mathrm{s}$, and an evident network structure was observed with SEM in the VES fracturing fluid after the measurement under $170 \mathrm{~s}^{-1}$ and $80{ }^{\circ} \mathrm{C}$ for 2 hours.

(3) The VES fracturing fluid showed to be a pseudoplastic fluid with favorable viscoelasticity, which resulted in the effective transport of the proppant. The maximum difference of the proppant mass proportion among the four segments of the simulated crack was $4.3 \%$. The average value of the proppant setting velocity was as low as $0.08 \mathrm{~g} / \mathrm{min}$.

(4) Compared to the formation water, the water CA could be decreased from 56.2 to $45.4^{\circ}$ and the water/oil IFT could be decreased from 19.5 to $1.6 \mathrm{mN} / \mathrm{m}$ by the fracturing fluid filtrate. Furthermore, there were no insoluble components in the VES fracturing fluid and the surfactant micelle could be destroyed in the presence of crude oil. In the combination of the above effects, the average loss rates of the matrix permeability and the crack conductivity were only $10.4 \%$ and $5.4 \%$ respectively.

\section{ASSOCIATED CONTENT}

\section{(s) Supporting Information}

The Supporting Information is available free of charge at https://pubs.acs.org/doi/10.1021/acsomega.0c05450.

(Table S1) Parameters of the core samples used for the evaluation of matrix damage, (Table S2) parameters of the simulated cracks used for the evaluation of conductivity damage, (Table S3) results of the matrix permeability damage, (Table S4) results of the crack conductivity damage, (Figure S1) cracked artificial cores prepared for conductivity damage test, (Figure S2) photos of the VES solution with different formulas, (Figure S3) variation of strain versus shear stress of the VES fluid, and (Figure S4) photo of the device used to test dynamic proppant transport (PDF)

\section{AUTHOR INFORMATION}

\section{Corresponding Author}

Chunsheng Pu - School of Petroleum Engineering, China University of Petroleum (East China), Qingdao, Shandong 266555, China; 이이.org/0000-0002-0724-5591; Email: chshpu_tx@126.com

\section{Authors}

Feifei Huang - School of Petroleum Engineering, China University of Petroleum (East China), Qingdao, Shandong 266555, China; 이이이.org/0000-0002-5579-6654

Leichao Lu - PetroChina Tarim Oilfield Company, Korla, Xinjiang 841000, China; 이이.org/0000-0003-03273162

Ze Pei - PetroChina Changqing Oilfield ChangBei Operating Company, Yulin, Shaanxi 710016, China

Xiaoyu Gu - School of Petroleum Engineering, Xi'an Shiyou University, Xi'an, Shaanxi 710065, China

Shujun Lin - Drilling and Production Equipment Research Institute, Lanzhou LS Petroleum Equipment Engineering Co., Ltd., Lanzhou, Gansu 730300, China

Feipeng Wu - School of Petroleum Engineering, China University of Petroleum (East China), Qingdao, Shandong 266555, China

Jing Liu - School of Petroleum Engineering, China University of Petroleum (East China), Qingdao, Shandong 266555,

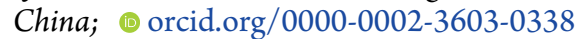

Complete contact information is available at:

https://pubs.acs.org/10.1021/acsomega.0c05450

\section{Notes}

The authors declare no competing financial interest.

\section{ACKNOWLEDGMENTS}

This work was supported by the National Key Research and Development Program of China (no. 2020YFA0711804), the Natural Science Foundation of China (no. 51874339 and 51904320), and the Natural Science Basic Research Plan in Shaanxi Province of China (no. 2020JQ-787 and 2020JQ775). The authors also thank Dr. Jingyang $\mathrm{Pu}$. for his linguistic assistance during the revision of this paper.

\section{REFERENCES}

(1) Liang, T.; Zhou, F.; Lu, J.; DiCarlo, D.; Nguyen, Q. Evaluation of wettability alteration and IFT reduction on mitigating water blocking for low-permeability oil-wet rocks after hydraulic fracturing. Fuel 2017, 209, 650-660.

(2) Roshan, H.; Al-Yaseri, A. Z.; Sarmadivaleh, M.; Iglauer, S. On wettability of shale rocks. J. Colloid Interface Sci. 2016, 475, 104-111.

(3) Liang, X.; Zhou, F.; Liang, T.; Wang, C.; Wang, J.; Yuan, S. Impacts of low harm fracturing fluid on fossil hydrogen energy production in tight reservoirs. Int. J. Hydrogen Energy 2020, 45, 21195-21204.

(4) Zhou, F.; Su, H.; Liang, X.; Meng, L.; Yuan, L.; Li, X.; Liang, T. Integrated hydraulic fracturing techniques to enhance oil recovery from tight rocks. Pet. Explor. Dev. 2019, 46, 1065-1072.

(5) Xue, L.; Chen, X.; Wang, L. Pressure transient analysis for fluid flow through horizontal fractures in shallow organic compound reservoir of hydrogen and carbon. Int. J. Hydrogen Energy 2019, 44, 5245-5253.

(6) Yang, X.; Mao, J.; Zhang, H.; Zhang, Z.; Zhao, J. Reutilization of thickener from fracturing flowback fluid based on Gemini cationic surfactant. Fuel 2019, 235, 670-676.

(7) Zhang, Y.; Mao, J.; Xu, T.; Zhang, Z.; Yang, B.; Mao, J.; Yang, $\mathrm{X}$. Preparation of a novel fracturing fluid with good heat and shear resistance. RSC Adv. 2019, 9, 1199-1207.

(8) Gai, S.; Nie, Z.; Yi, X.; Zou, Y.; Zhang, Z. Study on the Interference Law of Staged Fracturing Crack Propagation in Horizontal Wells of Tight Reservoirs. ACS Omega 2020, 5, 10327-10338. 
(9) Barbati, A. C.; Desroches, J.; Robisson, A.; McKinley, G. H. Complex Fluids and Hydraulic Fracturing. Annu. Rev. Chem. Biomol. Eng. 2016, 7, 415-453.

(10) Wang, F.; Chen, Q.; Lyu, X.; Zhang, S. Fracturing-Fluid Flowback Simulation with Consideration of Proppant Transport in Hydraulically Fractured Shale Wells. ACS Omega 2020, 5, 94919502.

(11) Zhao, L.; Chen, Y.; Du, J.; Liu, P.; Li, N.; Luo, Z.; Zhang, C.; Huang, F. Experimental Study on a new type of self-propping fracturing technology. Energy 2019, 183, 249-261.

(12) Huang, Q.; Liu, S.; Wang, G.; Cheng, W. Evaluating the changes of sorption and diffusion behaviors of Illinois coal with various water-based fracturing fluid treatments. Fuel 2021, 118884.

(13) Okere, C. J.; Su, G.; Zheng, L.; Cai, Y.; Li, Z.; Liu, H. Experimental, algorithmic, and theoretical analyses for selecting an optimal laboratory method to evaluate working fluid damage in coal bed methane reservoirs. Fuel 2020, 118513.

(14) Wang, T.; Xiao, J.; Wang, L.; Ma, A.; Tian, M.; Wang, C. Synthesis of gemini ammonium sulfobetaine and its proppant suspension and gel-breaking mechanisms. RSC Adv. 2020, 10, $7879-7886$.

(15) Mao, J.; Yang, X.; Wang, D.; Li, Y.; Zhao, J. A novel gemini viscoelastic surfactant (VES) for fracturing fluids with good temperature stability. RSC Adv. 2016, 6, 88426-88432.

(16) Samuel, M. M.; Card, R. J.; Nelson, E. B.; Brown, J. E.; Vinod, P. S.; Temple, H. L.; Qu, Q.; Fu, D. K. Polymer-Free Fluid for Fracturing Applications. SPE Drill. Completion 1999, 14, 240-246.

(17) Ezrahi, S.; Tuval, E.; Aserin, A. Properties, main applications and perspectives of worm micelles. Adv. Colloid Interface Sci. 2006, 128-130, 77-102.

(18) Al-Muntasheri, G. A. A Critical Review of HydraulicFracturing Fluids for Moderate- to Ultralow-Permeability Formations Over the Last Decade. SPE Prod. Oper. 2014, 29, 243-260.

(19) Huang, T.; Crews, J. B.; Agrawal, G. Nanoparticle Pseudocrosslinked Micellar Fluids: Optimal Solution for Fluid-Loss Control With Internal Breaking. In SPE International Symposium and Exhibition on Formation Damage Control, Society of Petroleum Engineers: Lafayette, Louisiana, USA, 2010; p 8.

(20) Mpelwa, M.; Zheng, Y.; Tang, S.; Pu, M.; Jin, L. Performance optimization for the viscoelastic surfactant using nanoparticles for fracturing fluids. Chem. Eng. Commun. 2020, 207, 1474-1482.

(21) Dai, C.; Zhang, Y.; Gao, M.; Li, Y.; Lv, W.; Wang, X.; Wu, Y.; Zhao, M. The Study of a Novel Nanoparticle-Enhanced Wormlike Micellar System. Nanoscale Res. Lett. 2017, 12, 431.

(22) Al-Muntasheri, G. A.; Liang, F.; Hull, K. L. NanoparticleEnhanced Hydraulic-Fracturing Fluids: A Review. SPE Prod. Oper. 2017, 32, 186-195.

(23) Zhao, J.; Yang, B.; Mao, J.; Zhang, Y.; Yang, X.; Zhang, Z.; Shao, Y. A Novel Hydrophobic Associative Polymer by RAFTMADIX Copolymerization for Fracturing Fluids with High Thermal Stability. Energy Fuels 2018, 32, 3039-3051.

(24) Zhang, Y.; Mao, J.; Zhao, J.; Zhang, W.; Liao, Z.; Xu, T.; Du, A.; Zhang, Z.; Yang, X.; Ni, Y. Preparation of a novel sulfonic Gemini zwitterionic viscoelastic surfactant with superior heat and salt resistance using a rigid-soft combined strategy. J. Mol. Liq. 2020, 114057.

(25) García, B. F.; Saraji, S. Linear rheology of nanoparticleenhanced viscoelastic surfactants. J. Mol. Liq. 2020, 112215.

(26) Hull, K. L.; Sayed, M.; Al-Muntasheri, G. A. Recent Advances in Viscoelastic Surfactants for Improved Production From Hydrocarbon Reservoirs. SPE J. 2016, 21, 1340-1357.

(27) Samuel, M.; Card, R. J.; Nelson, E. B.; Brown, J. E.; Vinod, P. S.; Temple, H. L.; Qu, Q.; Fu, D. K., Polymer-Free Fluid for Hydraulic Fracturing. In SPE Annual Technical Conference and Exhibition, Society of Petroleum Engineers: San Antonio, Texas, 1997; p 7.

(28) Al-Sadat, W.; Nasser, M. S.; Chang, F.; Nasr-El-Din, H. A.; Hussein, I. A. Laboratory evaluation of the effects of additives and $\mathrm{pH}$ on the thermorheological behavior of a viscoelastic zwitterionic surfactant used in acid stimulation. J. Pet. Sci. Eng. 2014, 122, 458467.

(29) Zhang, Y.; An, P.; Liu, X. A "worm"-containing viscoelastic fluid based on single amine oxide surfactant with an unsaturated C22-tail. RSC Adv. 2015, 5, 19135-19144.

(30) Kern, F.; Lequeux, F.; Zana, R.; Candau, S. J. Dynamic Properties of Salt-Free Viscoelastic Micellar Solutions. Langmuir 1994, 10, 1714-1723.

(31) Jenkins, K. M.; Wettig, S. D.; Verrall, R. E. Studies of the aggregation behavior of cyclic gemini surfactants. J. Colloid Interface Sci. 2002, 247, 456-462.

(32) Hussain, S. M. S.; Kamal, M. S.; Murtaza, M. Synthesis of Novel Ethoxylated Quaternary Ammonium Gemini Surfactants for Enhanced Oil Recovery Application. Energies 2019, DOI: 10.3390/ en12091731.

(33) Zhou, P.; Hou, J.; Yan, Y.; Wang, J.; Chen, W. Effect of Aggregation and Adsorption Behavior on the Flow Resistance of Surfactant Fluid on Smooth and Rough Surfaces: A Many-Body Dissipative Particle Dynamics Study. Langmuir 2019, 35, 81108120.

(34) Pei, X.; Xu, Z.; Song, B.; Cui, Z.; Zhao, J. Wormlike micelles formed in catanionic systems dominated by cationic Gemini surfactant: Synergistic effect with high efficiency. Colloids Surf., A 2014, 443, 508-514.

(35) Zhao, J.; Fan, J.; Mao, J.; Yang, X.; Zhang, H.; Zhang, W. High Performance Clean Fracturing Fluid Using a New Tri-Cationic Surfactant. Polymer 2018, DOI: 10.3390/polym10050535.

(36) Magid, L. J. The Surfactant-Polyelectrolyte Analogy. J. Phys. Chem. B 1998, 102, 4064-4074.

(37) Cates, M. E.; Candau, S. J. Statics and dynamics of worm-like surfactant micelles. J. Phys.: Condens. Matter 1990, 2, 6869-6892.

(38) Raghavan, S. R.; Kaler, E. W. Highly Viscoelastic Wormlike Micellar Solutions Formed by Cationic Surfactants with Long Unsaturated Tails. Langmuir 2001, 17, 300-306.

(39) Mao, J.; Tian, J.; Zhang, W.; Yang, X.; Zhang, H.; Lin, C.; Zhang, Y.; Zhang, Z.; Zhao, J. Effects of a counter-ion salt (potassium chloride) on gemini cationic surfactants with different spacer lengths. Colloids Surf., A 2019, 123619.

(40) Yang, C.; Song, Z.; Zhao, J.; Hu, Z.; Zhang, Y.; Jiang, Q. Selfassembly properties of ultra-long-chain gemini surfactants bearing multiple amide groups with high performance in fracturing fluid application. Colloids Surf., A 2017, 523, 62-70.

(41) Rose, G. D.; Foster, K. L. Drag reduction and rheological properties of cationic viscoelastic surfactant formulations. J. NonNewtonian Fluid Mech. 1989, 31, 59-85.

(42) Barati, R.; Liang, J. T. A Review of Fracturing Fluid Systems Used For Hydraulic Fracturing of Oil and Gas Wells. J. Appl. Polym. Sci. 2014, DOI: 10.1002/app.40735.

(43) Wei, Z.; Wei, X.; Sun, D.; Liu, J.; Tang, X. Crystalline structures and mesomorphic properties of gemini diammonium surfactants with a pendant hydroxyl group. J. Colloid Interface Sci. 2011, 354, 677-685.

(44) Ghumare, A. K.; Pawar, B. V.; Bhagwat, S. S. Synthesis and Antibacterial Activity of Novel Amido-Amine-Based Cationic Gemini Surfactants. J. Surfactants Deterg. 2013, 16, 85-93.

(45) Tawfik, S. M. Synthesis, surface, biological activity and mixed micellar phase properties of some biodegradable gemini cationic surfactants containing oxycarbonyl groups in the lipophilic part. $J$. Ind. Eng. Chem. 2015, 28, 171-183.

(46) Pisárčik, M.; Pupák, M.; Devínsky, F.; Almásy, L.; Tian, Q.; Bukovský, M. Urea-based gemini surfactants: Synthesis, aggregation behaviour and biological activity. Colloids Surf., A 2016, 497, 385396

(47) Smith, B. C.; Chou, L. C.; Zakin, J. L. Measurement of the orientational binding of counterions by nuclear magnetic resonance measurements to predict drag reduction in cationic surfactant micelle solutions. J. Rheol. 1998, 38, 73-83. 
(48) Gu, Q.; Hoo, K. A. Model-Based Closed-Loop Control of the Hydraulic Fracturing Process. Ind. Eng. Chem. Res. 2015, 54, 15851594.

(49) Aggarwal, A.; Agarwal, S.; Sharma, S. Viscoelastic Surfactants Based Stimulation Fluids with Added Nanocrystals and SelfSuspending Proppants for HPHT Applications. In Abu Dhabi International Petroleum Exhibition and Conference, Society of Petroleum Engineers: Abu Dhabi, UAE, 2014; p 9.

(50) Prieve, D. C. Intermolecular and surface forces : with applications to colloidal and biological systems. J. Colloid Interface Sci. 1987, 116, 300.

(51) Israelachvili, J. N.; Mitchell, D. J.; Ninham, B. W. Theory of self-assembly of hydrocarbon amphiphiles into micelles and bilayers. J. Chem. Soc., Faraday Trans. 2 1976, 72, 1525-1568.

(52) Wang, P.; Kang, W.; Yang, H.; Zhao, Y.; Yin, X.; Zhu, Z.; Zhang, $\mathrm{X}$. The $\mathrm{N}$-allyl substituted effect on wormlike micelles and salt tolerance of a C22-tailed cationic surfactant. Soft Matter 2017, $13,7425-7432$.

(53) Taliadorou, E.; Georgiou, G. C.; Moulitsas, I. Weakly compressible Poiseuille flows of a Herschel-Bulkley fluid. J. NonNewtonian Fluid Mech. 2009, 158, 162-169. 